\title{
Quando não se falava em inclusão: a história de vida do primeiro advogado cego formado no Brasil
}

\author{
Bento Selau* \\ Magda Floriana Damiani**
}

\section{Resumo}

Este trabalho tem como objetivo apresentar os achados de uma investigação que buscou reconstruir a história de vida de Walkírio Ughini Bertoldo, considerado o primeiro advogado cego brasileiro que concluiu a educação superior no país, no ano de 1957. Essa história será focada nos obstáculos por ele enfrentados, ao longo da trajetória por essa etapa da sua escolarização, analisando as estratégias por ele utilizadas para a superação de tais obstáculos. O processo investigativo, que resultou na história de vida do sujeito, foi guiado pelos procedimentos relativos ao método biográfico. Os dados foram coletados por meio de entrevistas com três informantes: dois colegas de faculdade, que depois passaram a ser, também, colegas de trabalho, e sua irmã. O corpus da investigação foi complementado com fontes documentais relativas à vida do sujeito. Os achados evidenciaram que a trajetória de Bertoldo pela educação superior foi marcada por sua grande dedicação e seu empenho; mostraram as resistências da instituição de ensino superior em aceitar o graduando cego e as estratégias utilizadas por ele para estudar, ainda que sem material adaptado; sua intensa atividade profissional; bem como sua relevante contribuição para o desenvolvimento social e a inclusão dos cegos na vida profissional e acadêmica.

Palavras-chave: Cegos; História de vida; Educação inclusiva.

\footnotetext{
* Professor Doutor da Universidade Federal do Pampa, Jaguarão, Rio Grande do Sul, Brasil.
}

** Professora Doutora da Universidade Federal de Pelotas, Pelotas, Rio Grande do Sul, Brasil. 


\section{When inclusion was not an issue: the life story of the first blind lawyer trained in Brazil}

\section{Abstract}

This work aims to present the findings of an investigation that sought to reconstruct the life story of Walkírio Ughini Bertoldo, considered to be the first blind lawyer to graduate, in Brazil, in 1957. The narrative focuses on the obstacles he faced along the trajectory through this stage of his schooling process, and analyzes the strategies he used to overcome them. The investigative process, which produced Bertoldo's life story, was guided by the biographical method. Data were collected through interviews with three informants: two college classmates, who later also became his coworkers, and his sister. The research corpus was supplemented by documentary sources related to the subject's life. The findings showed that the trajectory of Bertoldo through higher education was marked by his great dedication and commitment; showed the resistance of the higher education institution to accept blind undergraduates and strategies he used attend the course, in spite of the lack of adapted resources; his intense professional activity, as well as his outstanding contribution to social development and inclusion of the blind in professional and academic life.

Keywords: Blind people; Life story; Inclusive education.

\section{Introdução}

Este trabalho tem como objetivo apresentar os achados de uma investigação que buscou reconstruir a história de vida de Walkírio Ughini Bertoldo (1930-1998), considerado o primeiro advogado cego brasileiro a concluir a educação superior no país 1 , fato ocorrido no ano de 1957. O texto enfatiza os obstáculos por ele enfrentados, para concluir o curso de Direito, e analisa as estratégias por ele utilizadas para a superação desses obstáculos.

A história de vida de Bertoldo é notável, não somente pelo fato de ter enfrentado e superado uma série de dificuldades ${ }^{2}$, durante a educação superior, mas pelo fato de ele ter sido um estudante extremamente dedicado aos estudos, conseguindo concluir seu curso universitário com êxito - feito que considerava como mais um "degrau"3 para atingir o objetivo de adquirir conhecimentos que lhe autorizassem a atuar como advogado competente. Montar sua história de vida, com ênfase na educação superior, não foi, contudo, uma tarefa fácil: escrever sobre esse destacado advogado, sua brilhante inteligência e personalidade exemplar constituiu-se em um processo que apresentou limitações, em virtude da imensa gama de seus feitos e conquistas. A história de vida narrada ficou, assim, aberta a complementações.

Este texto mostra que a participação de deficientes, no âmbito do ensino superior, situação que hoje é conhecida por educação inclusiva, não é recente, embora extremamente rara, no passado. Assim, pode-se supor que a possibilidade de um cego ser estudante da educação superior não é, necessariamente, resultado do movimento de educação inclusiva, deflagrado há alguns anos. Entretanto, não é possível negar 
que esse movimento vem promovendo ajustes nos sistemas de ensino, para permitir que os deficientes tenham garantido seu direito de acesso a esse nível educacional (SIQUEIRA; SANTANA, 2010).

Segundo Pacheco e Costas (2005), a inclusão de deficientes, na educação superior de nosso país, apresenta-se como um novo desafio. As perspectivas de inclusão, fundamentadas nas normas estabelecidas pelo governo do Brasil, ainda estão em fase inicial, uma vez que, na prática, esse processo ainda precisa ser instituído. De acordo com as autoras, as iniciativas de apoio aos estudantes deficientes na educação superior são isoladas e, muitas delas, insuficientes para, efetivamente, auxiliar, nos estudos, os acadêmicos que requerem condições educacionais especiais.

Guimarães e Aragão (2010) indicam que a inclusão de deficientes na educação superior é um processo que se depara com as mesmas dificuldades envolvidas na inclusão de deficientes nos outros níveis educacionais: falta de recursos humanos especializados e capacitados; indisponibilidade da instituição educacional para desenvolver um trabalho pedagógico que atenda às necessidades específicas dos alunos; ausência de materiais adequados; presença de barreiras arquitetônicas; existência de preconceito e indiferença por parte de alunos e professores. Castro (2011) salienta que as universidades do Brasil vêm desenvolvendo algumas ações que visam incluir o deficiente na educação superior. Tais ações, no entanto, ainda são insuficientes para a permanência de alunos deficientes nessa etapa da escolarização.

A conclusão do ensino superior por um cego ainda chama a atenção da sociedade brasileira, em geral, mostrando que essa é uma difícil tarefa. Recentemente, o site mundovestibular ${ }^{4}$, reproduzindo reportagem divulgada pelo jornal Zero Hora, do dia 18 de setembro de 2009, enalteceu a apresentação do trabalho de conclusão de curso do acadêmico de Letras/Espanhol da Universidade Federal de Santa Maria (UFSM), Rodrigo Gonçalves da Silva. De acordo com o veiculado, o acadêmico era o primeiro estudante cego a concluir a educação superior na UFSM, fato ocorrido em 2009.

As demandas dos estudantes universitários deficientes nem sempre podem ser atendidas por meio de soluções pré-existentes (FERREIRA, 2007). Assim, pode-se perguntar: que ações podem ser realizadas, nesse nível educacional, para que o processo de inclusão desses estudantes se configure? ${ }^{5}$ Acredita-se que a resposta esteja na aplicação concomitante de três iniciativas (propostas) consideradas básicas para a efetivação da inclusão na universidade: a identificação dos alunos deficientes que frequentam a instituição e a definição das principais estratégias de acessibilidade que deverão ser adotadas para a permanência desses nos bancos universitários; o diálogo com eles para que se possam estabelecer ações conjuntas de facilitação do acesso as melhores condições de ensino; e, ainda, a elaboração de um projeto pedagógico específico que objetive o aprendizado desses estudantes, na mesma sala de aula frequentada pelos demais alunos. Nenhum desses aspectos foi levado em consideração pela instituição de ensino superior que recebeu Bertoldo, o que criou obstáculos adicionais para esse estudante. Assim, nessa discussão, um questionamento parece relevante: 
que estratégias foram utilizadas por Bertoldo, na década de 50 do século passado, para superar tais obstáculos?

O texto que segue está composto pelas seguintes partes: descrição dos procedimentos metodológicos da investigação; os primeiros passos em Tapejara e a vida escolar; vida acadêmica; atuação profissional após a realização da educação superior; considerações finais.

\section{Procedimentos metodológicos}

Para a realização desta pesquisa, recorreu-se às sugestões metodológicas propostas por Pujadas Muñoz (2002), quanto ao método biográfico e às possibilidades do uso de biografias nas ciências sociais. De acordo com o autor, a biografia constituise em um relato objetivo, construído pelo pesquisador, a partir de todas as evidências e documentação disponíveis sobre a pessoa investigada. Pujadas Muñoz (2002) indica que as biografias não utilizam, necessariamente, dados fornecidos pela pessoa biografada, o que permite que sejam realizadas investigações sobre sujeitos já falecidos.

Narrativas de pessoas-fonte e fontes documentais foram utilizadas com sucesso por outros pesquisadores da área da Educação, quando da realização de biografias de sujeitos já falecidos (ABRAHÃO, 2001; CHRISTOFOLI, 2001). Pujadas Muñoz (2002) chama a atenção para o fato de que uma das exigências para a realização de uma boa biografia é conseguir um informante adequado, ou seja, alguém que esteve imerso no universo social da pessoa cuja história se deseja narrar. Por esse motivo, procuraram-se pessoas ${ }^{6}$ que estiveram estreitamente relacionadas com Walkírio Ughini Bertoldo e, por meio delas, coletaram-se informações sobre a história de vida desse sujeito. $\mathrm{O}$ instrumento de coleta dessas informações foi a entrevista semi-estruturada ${ }^{7}$ (BOGDAN; BIKLEN, 1994; LÜDKE; ANDRÉ, 1986), que permitiu a realização de exploração, em profundidade, de temas previamente pensados e de outros que foram surgindo à medida que as entrevistas se desenvolviam e davam pistas para novos questionamentos.

Ao ser contatada, Léa Amaral, irmã de Bertoldo, mostrou-se disponível para participar da investigação. Em dia previamente marcado, ela foi entrevistada, em sua casa, ocasião na qual ofereceu uma série de documentos que auxiliaram na montagem da biografia de seu irmão. Esses documentos, artigos de jornais, na sua quase totalidade, publicados à época em que Bertoldo concluiu a educação superior, eram: Medeiros (1952); Um fato em foco (1958); Duarte (2000); Walkyrio Bertoldo (1954); Castilhos (1957); Cego para o mundo (1958); No Instituto Santa Luzia (1949).

Os encontros para a realização das entrevistas com dois ex-colegas (de faculdade e de trabalho) de Bertoldo foram igualmente proveitosos. Luiz Ribeiro Bilibio e Ivo Rodrigues Fernandes também forneceram relevantes informações a respeito do sujeito e de sua passagem pela educação superior. Eles, da mesma forma, ofereceram os seguintes documentos que se mostraram úteis para compor a biografia de seu antigo colega: currículum vitae de Bertoldo (sem data); Assassino de Concepcion condenado (1959); Condenado a 15 anos de cadeia o matador da bela espanhola (1959). 
Além desse conjunto de fontes, entrou-se em contato com a Pontifícia Universidade Católica do Rio Grande do Sul (PUCRS), instituição na qual Bertoldo cursou a faculdade, para solicitar seus registros acadêmicos. Como tal solicitação somente poderia ser feita por um familiar do sujeito, entrou-se novamente em contato com outra de suas irmãs, Ermínia Fernandes ${ }^{8}$, para fazê-la. Por meio da solicitação, teve-se acesso ao histórico escolar e ao relatório do concurso vestibular do biografado.

Os dados coletados foram trabalhados pelo método de análise textual discursiva, proposto por Moraes (2003), que é constituído por um misto de análise de conteúdo e de discurso. Os resultados dessa análise são apresentados na sequência.

\section{Os primeiros passos em Tapejara e a vida escolar}

Walkírio Ughini Bertoldo nasceu em Tapejara, cidade do interior do Estado do Rio Grande do Sul (RS), Brasil, em 10 de maio de 1930. Era filho de Arnaldo Bertoldo, comerciante, e de Thereza Ughini Bertoldo, dona de casa. Bertoldo era o terceiro dos seis filhos do casal, o único filho homem. Sua cegueira foi constatada em 1931, sendo consequência de uma meningite contraída quando Bertoldo tinha quase, um ano de idade. Por essa condição, foi enviado por seus pais para ser estudante, em sistema de internato, no Instituto Santa Luzia, em Porto Alegre (RS), quando tinha oito anos de idade. Neste local, Bertoldo aprendeu a ler e escrever por meio do sistema braille. Também aprendeu a tocar piano, violão, gaita e alguns instrumentos de sopro, assim como estudou línguas estrangeiras. Por opção, Bertoldo nunca utilizaria uma bengala, como instrumento auxiliar, nos seus deslocamentos.

Presidiu o Grêmio Estudantil da instituição, por várias gestões, sendo responsável pela edição da revista "A Rio grandense", editada em braille e remetida para diversos países. Durante essa época, há relatos registrados que demonstram o interesse de Bertoldo em ingressar na educação superior. Prova disso pode ser encontrada, por exemplo, em discurso proferido em 1955, por ocasião do lançamento da pedra fundamental do Instituto Santa Luzia, quando salientou que se diplomar seria o seu ideal (NO INSTITUTO SANTA LUZIA, 1949). Bertoldo fez parte do primeiro grupo de ginasianos formados nesse Instituto.

O caminho para a educação superior de Bertoldo, entretanto, não foi tão simples como a entrada no Instituto Santa Luzia. Antes de ser aluno de uma instituição de ensino superior, deveria passar, ainda, pelo curso secundário9. A escolha de Bertoldo e de sua família foi a de cursá-lo no Colégio Marista Rosário, de Porto Alegre, justamente porque se localizava perto da casa de um familiar, na qual o sujeito residia.

A possibilidade de ingressar no Curso Clássico (de nível secundário) do Colégio Rosário, no ano de 1950, foi algo que ocorreu sob muitas condições, impostas pela direção da instituição: uma delas, prescrita e firmada entre a direção do colégio e a família de Bertoldo, foi a de que a presença de um aluno cego não trouxesse nenhum tipo de problema ou contratempo aos outros alunos, aos professores, ou ao Colégio como um todo. Aceitas essas condições, o secundário foi cursado sem complicações entre Bertoldo e seus colegas. Pelo contrário, representou um período de alegria, durante a trajetória escolar, especialmente porque foi no Colégio Rosário que Bertoldo 
conheceu dois de seus melhores amigos: Paulo Merlot e Pedro Simon ${ }^{10}$, com os quais conviveu durante a educação superior.

Após a conclusão do secundário, sua meta de entrar para a educação superior estava bem definida. Desejava cursar Direito na PUCRS, juntamente com seu colega e amigo Pedro Simon. Antes de sua entrada na universidade, todavia, outros obstáculos foram colocados, os quais serão discutidos a seguir.

\section{A vida acadêmica}

Se, por um lado, a afirmação sobre o pioneirismo de Bertoldo, na conclusão de curso de nível superior no Brasil, deixa dúvidas, isso não ocorre com a que enfatiza seu pioneirismo como advogado cego. Algumas reportagens da mídia impressa apontam, enfaticamente, Bertoldo como o primeiro cego brasileiro a diplomar-se em instituição nacional de nível superior (MEDEIROS, 1952; UM FATO EM FOCO, 1958; DUARTE, 2000; WALKYRIO BERTOLDO, 1954). Entretanto, há informações de que Edison Ribeiro Lemos, um ilustre cego carioca, teria se formado em Geografia e História na Universidade Federal Fluminense em 1956, neste caso, um ano antes do que Bertoldo (PERFIL, 2005). As evidências de que ele foi o primeiro cego formado em Direito no Brasil (CASTILHOS, 1957; CEGO PARA O MUNDO, 1958; ASSASSINO DE CONCEPCION CONDENADO, 1959), por seu turno, não foram contrapostas.

Os entrevistados, que participaram desta pesquisa, também confirmaram essa informação, chamando a atenção para um fato que foi além das reportagens jornalísticas da época, ou seja, o obstáculo inicial imposto pela PUCRS: a declaração de impossibilidade de ele cursar o ensino superior, justamente por ser cego.

Segundo os entrevistados, quando Bertoldo procurou a PUCRS, com o propósito de prestar o exame vestibular, esse direito lhe foi negado, sob a alegação de que era cego. Impelido pela vontade de continuar seus estudos, e impedido de fazê-lo no Brasil, procurou uma instituição estrangeira, para averiguar a possibilidade de nela estudar: a faculdade de Direito da Universidade de Buenos Aires, na Argentina. Nessa instituição, foi-lhe concedida chance de prestar exame vestibular, por meio de parecer escrito. De posse desse parecer, Bertoldo entrou novamente em contato com a direção da PUCRS, para provar que era, sim, possível um cego cursar o ensino superior. Com base em tal documento, os gestores da PUCRS aceitaram que ele prestasse vestibular.

No Brasil, da década de 1950, havia ainda muitas formas de preconceito contra o deficiente visual, fossem elas nas instâncias de pessoa física ou jurídica. Essas formas de preconceito eram relativas, principalmente, à capacidade de autossuficiência do cego. Isso significa que o deficiente visual era considerado um "coitadinho", alguém digno de pena, ou mesmo alguém incapaz para o trabalho intelectual. Essa visão relativa ao cego não era privilégio do povo brasileiro. Diniz (2007) relata, por exemplo, que em 1960, nos Estados Unidos da América (EUA), os cegos eram proibidos de executar as atividades mais corriqueiras, tais como frequentar um restaurante, hospedar-se em um hotel, ou viajar de trem. A autora aponta que muitas dessas proibições não eram reguladas por leis, mas incorporadas pelas pessoas não-deficientes 
que, em geral, consideravam inadmissível um cego transitar, normalmente, por espaços públicos.

No concurso vestibular que Bertoldo prestou, em 1953, obteve as seguintes notas: 8,5 em Latim, 8,8 em Português e 9,5 em Francês, o que lhe garantiu o primeiro lugar na PUCRS, em dois cursos: Direito e Filosofia. Ele optou pelo curso de Direito. Durante as aulas na faculdade de Direito, os professores davam a Bertoldo o mesmo tratamento que era dado aos demais estudantes. Ivo Rodrigues Fernandes indica que, na sala de aula da educação superior, não havia nenhuma "colher de chá", nenhum professor "passava a mão em sua cabeça" pelo fato de ser ele cego.

Seus ex-colegas apontam que ele era muito estudioso. Sua dedicação e esforço, durante o ensino superior, fatalmente, levaram-no a trilhar uma carreira profissional com muita competência. Luiz Ribeiro Bilibio lembra que os debates teóricos que teve com Bertoldo colaboraram com a aprendizagem do primeiro sobre temas da área jurídica: "[á]s vezes nós chegávamos a debater problemas que pareciam sem solução. Depois de debater, chegávamos a soluções e terminávamos levantando teses que eram vitoriosas. Isso aconteceu muitas vezes!".

Seu aproveitamento nas disciplinas foi exemplar. Bertoldo foi aprovado em todas as disciplinas que cursou no ensino superior. Da sua grade curricular, destacamse, de cada série ${ }^{11}$, as seguintes disciplinas, com suas notas mais altas: $1^{\underline{a}}$ série, Teoria Geral do Estado, 8,5; $2^{\underline{a}}$ série, Ciência das Finanças, 8,7; 3 로érie, Direito Internacional Público, 8,0; 4aㅗ série, Medicina Legal, 9,2; 5ª̣ série, Filosofia do Direito, 8,0. A PUCRS não informou o seu coeficiente de rendimento, porém os entrevistados salientaram que suas notas estavam entre as mais altas da sua turma.

A universidade não investiu em nenhum tipo de adequação, instrumental ou em termos dos materiais para estudo, com vistas a facilitar as atividades acadêmicas do sujeito. Quem tomou a providência de realizar diferentes adaptações, para que ele pudesse concluir seus estudos em Direito e adquirir instrumental que facilitasse sua trajetória pela educação superior, foi o próprio Bertoldo e sua própria família. Os entrevistados mencionaram três dessas providências:

1) Um secretário: durante o curso, Bertoldo não contava com livros, no formato braille, para estudar. Essa situação dificultava sua interação com o conteúdo das disciplinas. Por esse motivo, sua família contratou um secretário, um rapaz que o acompanhava nos estudos, em turno inverso ao das aulas na faculdade. A tarefa desse secretário era a de fazer leituras do material impresso à tinta, recebido dos professores, dos livros de Direito, emprestados pela biblioteca da universidade, enfim, de todo o material que fosse importante para sua formação e que o sujeito não conseguia ler pessoalmente.

2) A aquisição de um gravador: o pai de Bertoldo mandou buscar, dos EUA, um gravador para que ele pudesse gravar as aulas - pois, no Brasil, esse equipamento não existia. Segundo Léa Amaral, quando estava em casa, após as aulas na faculdade, Bertoldo escutava, novamente, as falas dos professores. 
3) A compra de uma máquina de datilografia: a família de Bertoldo também precisou providenciar a compra de uma máquina de datilografia (adquirida com mais facilidade do que o gravador, pois existia no Brasil). Trabalhos e provas eram sempre entregues datilografados, por Bertoldo, conforme informou Ivo Rodrigues Fernandes.

Todas as adaptações mencionadas foram (e ainda o seriam hoje) um tanto dispendiosas e somente foram possibilitadas pela boa situação socioeconômica da família de Bertoldo. Fosse ele uma pessoa com poucos recursos financeiros, naquela época, começo da segunda metade do século XX, provavelmente dificuldades, ainda maiores do que as dele, para cursar a educação superior.

Analisando-se esta situação, percebe-se que a universidade que o sujeito frequentava eximia-se de qualquer tipo de responsabilidade pela formação do deficiente: ou ele se adaptava à realidade, ou não estudava. Assim, a conclusão do curso superior, por Bertoldo, foi, para a época, um acontecimento incrível, fato que chamou a atenção da imprensa nacional (MEDEIROS, 1952; UM FATO EM FOCO, 1958; WALKYRIO BERTOLDO, 1954; CASTILHOS, 1957; CEGO PARA O MUNDO, 1958). Quando, em 21 de dezembro de 1957, concluiu o curso de Direito, o então Presidente da República, Juscelino Kubitschek de Oliveira, e seu vice-presidente, João Goulart, enviaram mensagens de congratulações e cumprimentos, apontando Bertoldo como um destacado exemplo de brilhantismo em seu curso (DUARTE, 2000).

Embora o orador da turma tenha sido Pedro Simon, Bertoldo recebeu uma homenagem e foi-lhe concedido o direito de também discursar, conforme informou Fernandes. A fala de Bertoldo, naquela ocasião, foi gravada pela revista O Cruzeiro. Seu registro visual era transmitido em salas de cinema da época, antes dos filmes, segundo relatou sua irmã. Durante esse discurso, o sujeito pronunciou, pela primeira vez, a seguinte frase: "Calai-vos ó falsos preconceitos. Deixai vir à luz a voz da razão". Essa frase foi repetida, diversas vezes, durante sua vida.

A Figura 1 mostra a reportagem no jornal A Hora, de 17 de abril de 1954 (WALKYRIO BERTOLDO, 1954), que destaca um pouco da trajetória escolar de Bertoldo: a educação básica, a faculdade, a realização de um juri simulado, durante o curso. Essa reportagem é uma das que o aponta como o primeiro universitário cego formado no Brasil. 


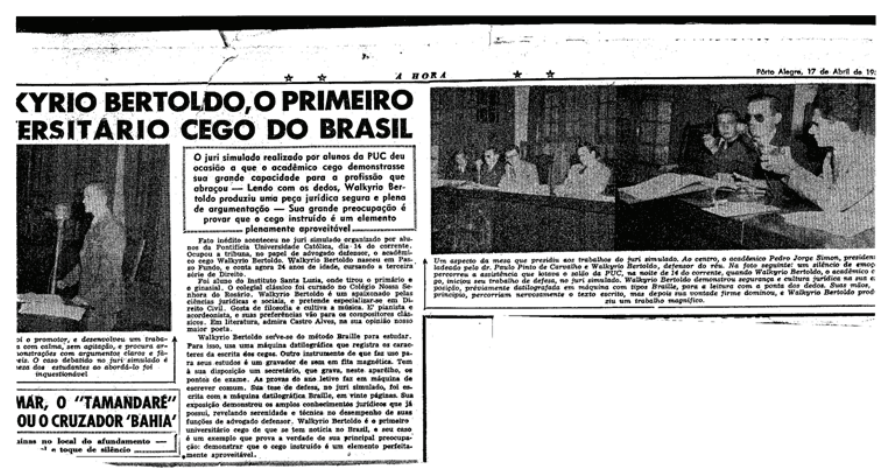

Figura 1 - Notícia sobre a colação de grau de Bertoldo.Fonte: Walkyrio Bertoldo (1954).

A educação superior era avaliada, por Bertoldo, como um "degrau", uma tarefa a mais para atingir os seus objetivos. Por esse motivo, Bilibio comenta que nunca passou pela cabeça desse sujeito desistir de cursar a faculdade, mesmo nos momentos de maior dificuldade: "Ele tinha uma determinação, uma vontade muito grande. E deu exemplos magníficos [...] ele abriu as portas. Ele tinha uma determinação, uma força de vontade fora do comum". Os depoimentos dos seus ex-colegas de educação superior demonstram que a vontade de Bertoldo, de galgar espaços mais altos na área profissional, foi determinante para que ele conseguisse transpor diferentes obstáculos e concluir o curso superior como um dos estudantes com as notas mais elevadas:

[p]ara mim, foi um enriquecimento que eu tive: em amizade, em mais profundidade dos conhecimentos jurídicos, trocando ideias com ele. Esses dias, eu assisti a uma entrevista do primeiro astronauta dos EUA a ir para a lua. Ele disse que a pessoa que tiver determinação e quiser as coisas, ela consegue o impossível. Eu tenho a convicção que a pessoa que tem determinação e tem vontade e não se deixa abater, consegue realizar todos os seus sonhos. E o Walkírio conseguiu o que parecia o impossível. (BILIBIO)

\section{Atuação profissional após a realização da Educação Superior}

Após a realização da educação superior, Bertoldo abriu um escritório de advocacia, em Porto Alegre, na companhia profissional de Pedro Simon, Ivo Rodrigues Fernandes e Luiz Ribeiro Bilibio, no ano de 1957. Trabalhou intensamente nesse escritório, enquanto desenvolvia outras atividades profissionais. Uma dessas atividades era a de procurador geral da prefeitura do município de Porto Alegre, cargo alcançado com a realização de concurso público. O relato de sua irmã aponta, entretanto, que a conquista desse cargo não foi fácil. Havia um bom número de vereadores desse município que era desfavorável a sua inscrição como candidato no concurso. Foi necessária a intercessão do (então) prefeito de Porto Alegre, Leonel Brizola, para que Bertoldo pudesse se candidatar à vaga. Bertoldo foi nomeado procurador geral da Prefeitura de 
Porto Alegre, em 21 de março de 1959. Sobre a atuação profissional do sujeito, Luiz Ribeiro Bilibio relatou que

Walkírio se tornou um brilhante advogado; brilhante! Ele escrevia muito bem. Tinha um raciocínio jurídico perfeito. Ele fez trabalhos brilhantes. Ele tinha uma facilidade grande para escrever. Ele pegava uma questão, ficava pensando, chamava o secretário, começava a falar e não parava mais. Trabalhava em temas de profundidade. Não eram "trabalhinhos". Eram trabalhos altamente respeitáveis. Nas audiências, era duro, trabalhava de igual para igual com os outros advogados. Aliás, melhor do que muitos deles!

Bertoldo ainda realizou diferentes atividades, algumas delas consideradas pelos entrevistados como as primeiras de um cego no Brasil. São as seguintes, segundo seu currículum vitae:

- Conquistou, durante a universidade, o direito de os cegos estudarem em classes normais no Brasil (sem data do evento);

- Elaborou, juntamente com um grupo de 18 pessoas, o primeiro requerimento jurídico, junto ao Tribunal Superior Eleitoral, para cegos exercerem o direito do voto no Brasil, em 1958;

- Foi o primeiro cego a votar no Brasil (sem data do evento);

- Em 1959, foi para os EUA, a convite dos diretores da "American Foundation For Overseas Blind", para conhecer a situação dos cegos naquele país ${ }^{12}$

- Foi nomeado Chefe do Serviço Especializado na Indústria do Rio Grande do Sul (sem data do evento) e nesse cargo, conseguiu emprego para muitos deficientes visuais;

- Em seu primeiro júri, o primeiro de um advogado cego no Brasil (ASSASSINO DE CONCEPCION CONDENADO, 1959), no ano de 1959, obteve a condenação de Vicente Raul D'Onófrio, argentino acusado de ter matado a espanhola Concepción Guerra Pidal;

- Em 1976, fundou a Associação Brasileira dos Pais e Amigos das Vítimas da Talidomida (ABVT), colocando-se como advogado de todas as vítimas;

- Celebrou, em 1982, um acordo judicial que contemplava todas as vítimas da Talidomida do Brasil, contendo: indenização, a ser paga pelos laboratórios; pensão vitalícia, de responsabilidade do governo do Brasil; e, ainda, pensões provenientes do governo alemão e de uma fundação daquele país;

- Foi sócio da Associação de Cegos do Rio Grande do Sul e Sócio Fundador da Associação de Cegos Louis Braille, na qual, por sua contribuição, foi nomeado Sócio Benemérito;

- Na gestão de 1983 a 1985, atuou como presidente desta entidade;

- Em 10 de junho de 1987, no governo de Pedro Simon, no Estado do Rio Grande do Sul, assumiu a presidência da Fundação Rio-Grandense de Atendimento ao Excepcional (FAERS), sugerindo a mudança de forma e 
nome desta fundação para Fundação de Auxílio ao Deficiente e Superdotado do Rio Grande do Sul (FADERS).

Seu falecimento ocorreu em 22 de julho de 1998. Logo em seguida, a prefeitura de Porto Alegre homenageou-o, colocando seu nome em uma praça da cidade ${ }^{13}$. Ao descrever todos os feitos de Bertoldo, sua irmã reforçou: "O mais prudente é falar que o Walkírio conseguiu alcançar todos esses espaços por competência, nunca por amizade".

\section{Considerações finais}

A história de Bertoldo sugere que ele conseguiu vencer os obstáculos a sua formação de nível superior, alcançando seus objetivos, por ter persistido intensamente nessa busca, guiado por sua vontade (VYGOTSKI, 1997). Este texto cumpre o papel de mostrar que o esforço deste grande brasileiro terminou por abrir as portas da universidade para muitos outros cegos, revelando, também, a capacidade de trabalho que pode ter uma pessoa, mesmo em face de uma deficiência.

Acreditar na educação, como meio de superação e como fator que auxilia na promoção da independência do cego, foram ideias já lançadas por Vygotski, (1997), no início do século XX. A pertinência de tais ideias parece ter sido demonstrada pela maneira como esse ilustre brasileiro construiu sua identidade e carreira profissionais, apesar das imensas dificuldades enfrentadas. Embora, atualmente, o processo de inclusão de deficientes no ensino regular já tenha avançado enormemente, a história de vida de Bertoldo merece ser divulgada como forma de mostrar que, mesmo em tempos em que esse processo ainda não havia iniciado oficialmente, foi possível a um cego concluir, com brilhantismo, o curso superior.

Percorrer o trajeto desenhado pelo processo educacional na educação básica e, posteriormente, na educação superior, representa uma importante via de acesso profissional e social para todas as pessoas, independentemente de suas capacidades ou dificuldades. Assim, um debate aberto e abrangente sobre as necessidades que a universidade ainda deve atender, para a inclusão de cegos, pode favorecer a entrada de um número maior de pessoas nesse espaço de escolarização. A história de vida de Bertoldo pode ser utilizada como base para esse debate, especialmente porque os obstáculos, por ele enfrentados, exemplificam as atitudes que as universidades não podem mais repetir, quando receberem um aluno cego. Igualmente, as estratégias por ele utilizadas para a superação desses obstáculos ilustram o que pode ser feito pela sociedade, pelas instituições de ensino superior, pelas famílias e pelo próprio cego para chegar a concluir, com méritos, esta etapa da escolarização.

\section{Referências}

ABRAHÃO, M. H. M. B. Zilah Mattos Totta: síntese da educação e do educador. In: ABRAHÃO, M. H. M. B. (Org.). História e histórias de vida: destacados educadores fazem a história da educação rio-grandense. Porto Alegre: EDIPUCRS, 2001.

ASSASSINO de Concepcion condenado: quinze anos! Fôlha da Tarde, Porto Alegre, 13 jun. 1959.

A UFSM pode ter o primeiro cego a concluir graduação da universidade. Mundovestibular, 18 set. 2009. Disponivel em: http://www.mundovestibular.com.br/articles/6958/1/UFSM-pode-ter-o-primeiro-cego-a-concluirgraduacao-da-universidade-/Paacuteginal.html. Acesso em: 21 dez. 2011.

Revista Educação Especial | v. 27 | n. 49 | p. 417-430| maio/ago. 2014

Santa Maria 
BOGDAN, R. C.; BIKLEN, S. K. Investigação qualitativa em educação: uma introdução à teoria e aos métodos. Porto: Porto Editora, 1994.

CAIADO, K. R. M. Aluno deficiente visual na escola: lembranças e depoimentos. Campinas: Autores Associados, 2003.

CASTILHOS, R. Jovem cego forma-se em Direito e inicia a batalha para readaptação dos irmãos de infortúnio. Folha da Tarde, Porto Alegre, ago. 1957.

CASTRO, S. F. Ingresso e permanência de alunos com deficiência em universidades públicas brasileiras. 2011. 278f. Tese (Doutorado em Educação Especial)-Centro de Educação e Ciências Humanas, Universidade Federal de São Carlos, São Carlos.

CEGO para o mundo. O Cruzeiro, 13 set. 1958.

CHRISTOFOLI, M. C. P. Irmão Inocêncio Luiz: uma vida de opção pela educação dos excluídos. In: ABRAHÃO, M. H. M. B. (org.). História e histórias de vida: destacados educadores fazem a história da educação rio-grandense. Porto Alegre: EDIPUCRS, 2001.

CONDENADO a 15 anos de cadeia o matador da bela espanhola. A Hora, Porto Alegre, 13 jun. 1959.

DELPINO, M. Facilidade e dificuldades encontradas pelos alunos com deficiência visual no curso superior. 2004. 14lf. Dissertação (Mestrado em Distúrbios do Desenvolvimento), Universidade Presbiteriana Mackenzie, São Paulo.

DINIZ, D. O que é deficiência. São Paulo: Brasiliense, 2007.

DUARTE, M. O primeiro universitário cego - formado em Direito advogou com Pedro Simon - fundou importantes entidades - Walkírio Ughini Bertoldo. O Nacional, Passo Fundo, p. 23, 14 e 15 out. 2000.

PERFIL: Edison Ribeiro Lemos: tomba um combatente. Revista Benjamin Constant, Rio de Janeiro, ed. 30, p. 1-3, abr. 2005. Disponível em: 〈http://www.ibc.gov.br/?catid=4\&citemid=10028〉. Acesso em: 21 out. 2013.

FERREIRA, S. L. Ingresso, permanência e competência: uma realidade possível para universitários com necessidades educacionais especiais. Revista Brasileira de Educação Especial, Marília, v. 13, n. 1, p. 43-60, jan./abr. 2007.

GUIMARÃES, C. F.; ARAGÃO, A. L. A. Reflexões sobre as políticas e ações institucionais: a caminho da inclusão de pessoas com deficiência no ensino superior de Natal-RN. In: IV Seminário Nacional Sobre Educação e Inclusão Social de Pessoas com Necessidades Especiais, 2010. Anais IV Seminário Nacional sobre Educação e Inclusão Social de Pessoas com Necessidades Especiais. Natal: UFRN, 2010.

LÜDKE, M.; ANDRÉ, M. E. D. Pesquisa em Educação: abordagens qualitativas. São Paulo: EPU, 1986.

MASINI, E. F. S.; BAZON, F. V. M. A inclusão de estudantes com deficiência, no ensino superior. In: Reunião anual da ANPED, 28, 2005, Caxambu. Anais da 28ª Reunião Anual. Caxambu: ANPEd, 2005. Disponível em: 〈http://www.anped.org.br/reunioes/28/inicio.htm〉. Acesso em: 22 fev. 2011.

MAZZONI, A. A.; TORRES, E. F. A percepção dos alunos com deficiência visual acerca das barreiras existentes no ambiente universitário e seu entorno. Revista Benjamin Constant, Rio de Janeiro, ed. 30, p. 1-12, abr. 2005.

MEDEIROS, R. F. Cego. O Cruzeiro, Rio de Janeiro, 15 ago. 1952.

MORAES, R. Uma tempestade de luz: a compreensão possibilitada pela análise textual discursiva. Ciência \& Educação, Bauru, v. 9, n. 2, p. 191-211, 2003. Disponível em: 〈http://www.scielo.br/scielo.php?scrip$\mathrm{t}=$ sci_arttext\&pid=S1516-73132003000200004\& $\&$ lng=en\&enrm=iso\&tlng=pt . Acesso em: 14 mai. 2010.

NOGUEIRA, M. L. L. A importância dos pais na educação segundo a percepção de universitários deficientes visuais. Revista Benjamin Constant, Rio de Janeiro, ed. 23, p. 1-8, dez. 2002.

NO Instituto Santa Luzia: Bertoldo, o primeiro cego de nascença que se formará em Direito no Brasil. Folha da Tarde, 15 jun. 1949.

PACHECO, R. V.; COSTAS, F. A. T. O processo de inclusão de acadêmicos com necessidades educacionais especiais na Universidade Federal de Santa Maria. Revista Educação Especial, Santa Maria, n. 27, 2005. Disponível em: 〈http://coralx.ufsm.br/revce/ceesp/2006/01/rl2.htm〉. Acesso em: 22 fev. 2011.

PUJADAS MUÑOZ, J. J. El método biográfico: el uso de las historias de vida en ciencias sociales. 2. ed. Madrid: Centro de Investigaciones Sociológicas, 2002. 
SELAU, B. Fatores associados à conclusão da educação superior por cegos: um estudo a partir de L. S. Vygotski. 2013. 287f. Tese (Doutorado em Educação)-Faculdade de Educação, Universidade Federal de Pelotas, Pelotas.

SIQUEIRA, I. M.; SANTANA, C. S. Propostas de acessibilidade para a inclusão de pessoas com deficiências no Ensino Superior. Revista Brasileira de Educação Especial, Marília, v.16, n.1, p.127-136, jan./abr. 2010.

UM fato em foco. O Cruzeiro, Rio de Janeiro, 11 jan. 1958.

VYGOTSKI, L. S. Obras Escogidas: Fundamentos de Defectología. Madrid: Visor, 1997.

WALKYRIO B. O primeiro universitário cego do Brasil. A Hora, Porto Alegre, 17 abr. 1954.

\section{Notas}

${ }^{1}$ De acordo com Medeiros (1952), os outros brasileiros cegos com graduação superior, naquela mesma época, realizaram essa formação em países estrangeiros.

${ }^{2}$ Algumas das dificuldades pelas quais passaram alguns estudantes cegos, que se propuseram a cursar a educação superior no Brasil, foram relatadas por diferentes pesquisadores (DELPINO, 2004; MAZZONI e TORRES, 2005; CAIADO, 2003; MASINI e BAZON, 2005; SELAU, 2013).

${ }^{3}$ Metáfora utilizada por Bertoldo para comunicar o sentido de elevar-se, ou conseguir o desejado, segundo informação de sua irmã.

${ }^{4}$ A UFSM pode ter o primeiro cego a concluir graduação da universidade. Mundovestibular, 18 set. 2009. Disponível em: http://www.mundovestibular.com.br/articles/6958/1/UFSM-pode-ter-o-primeiro-cego-a-concluir-graduacaoda-universidade-/Paacuteginal.html>. Acesso em: 21 dez. 2011.

${ }^{5}$ As ações referem-se à tarefa do professor e da instituição superior de ensino; Nogueira (2002) observou que, em diferentes casos, os pais desempenham papel fundamental no acompanhamento e na ajuda aos cegos, desde a educação básica até a educação superior.

${ }^{6}$ Agradece-se as contribuições de Léa Amaral, graduada em Filosofia pela PUCRS; Luiz Ribeiro Bilibio, graduado em Direito pela PUCRS; Ivo Rodrigues Fernandes, graduado em Direito pela PUCRS. Essas pessoas permitiram a divulgação de seus nomes.

${ }^{7}$ As transcrições das entrevistas foram devolvidas aos participantes, para que pudessem ser validadas.

${ }^{8}$ Agradecemos, igualmente, a Ermínia Fernandes, pela contribuição feita a esta pesquisa. Ela também autorizou a publicação de seu nome.

${ }^{9}$ Atual ensino médio.

${ }^{10}$ Pedro Simon é senador da república. Procurado pelos pesquisadores, o senador expressou vontade de falar sobre Bertoldo, bem como sobre a relação profissional e amigável que com ele teve. No entanto, o senador não conseguiu espaço em sua agenda para conceder a entrevista.

${ }^{11}$ A faculdade, com duração de 5 anos, era dividida em 5 séries. Cada uma dessas séries correspondia a um ano de curso.

${ }^{12}$ As passagens para Bertoldo e mais um acompanhante foram custeadas pela Viação Aérea Rio Grandense (VARIG), como presente pela graduação em curso superior.

${ }^{13}$ Praça “Walkírio Ughini Bertoldo", localizada no Bairro Rubem Berta, CEP 91150-145.

\section{Correspondência}

Bento Selau - Universidade Federal do Pampa, Campus Jaguarão.Rua Conselheiro Diana, 650, Kennedy, CEP: 96300-000, Jaguarão, Rio Grande do Sul - Brasil.

E-mail: bentoselau@unipampa.edu.br - flodamiani@gmail.com

Recebido em 04 de julho de 2013

Aprovado em 1o- de novembro de 2013 
